\title{
The Future of the Past Is the Present: The Role of the UEMS/EBNM in the Current Challenge of Educating Nuclear Medicine Specialists
}

\author{
Savvas Frangos, Roland Hustinx, Ariane Boubaker, Teresio Varetto, John O. Prior, Mirzaei Siroos, and Lorenzo Maffioli \\ UEMS Section of Nuclear Medicine and European Board of Nuclear Medicine, Vienna, Austria
}

$\mathbf{T}$ enne des Médecins Spécialistes), or UEMS, was established in 1958 as the representative organization for medical specialists in the European Union (EU) and in the European Economic Area (1). With a current membership of 37 countries, it is the representative organization of the national associations of medical specialists in the EU and its associated countries. Its structure consists of a council responsible for and working through 43 specialist sections and their European boards, addressing specialty-specific training and incorporating representatives from those responsible for training (medical societies, colleges, and universities). One of the roles of the UEMS is the promotion and harmonization of the highest level of training of medical specialists within and beyond the EU and the European Economic Area. It must meet the standards and criteria laid down by the appropriate national training authority and by the individual training programs and be in accordance with the recommendations of the UEMS charter on training of medical specialists and chapter 6 thereof (https://www.uems.eu/_data/assets/pdf_file/ 0011/1415/906.pdf). Postgraduate curricula should also refer to the World Federation for Medical Education global standards (2) for quality improvement in postgraduate medical education, adopted in 2002.

The formal recognition of nuclear medicine as a separate medical specialty within the UEMS was finally achieved by Desmond Croft in 1989 (3), after 8 long years of delicate negotiations. The Section of Nuclear Medicine appeared in 1990 within the UEMS, and the European Board of Nuclear Medicine (EBNM) was created in 1993. In 2003 the UEMS Section of Nuclear Medicine and the EBNM merged (UEMS/EBNM) "in order to unify and facilitate activities, mainly to improve and harmonize the training of nuclear medicine throughout European countries to the highest possible standards."

The UEMS/EBNM consists of 4 committees: education and syllabus, accreditation of nuclear medicine departments and training centers, continuing medical education (CME)/continuing professional development (CPD) accreditation, and fellowship examination.

\footnotetext{
Received Nov. 26, 2017; revision accepted Nov. 28, 2017.

For correspondence or reprints contact: Savvas Frangos, UEMS/EBNM, Schmalzhofgasse 26, 1060 Vienna, Austria.

E-mail: office@uems.eanm.org

Published online Dec. 21, 2017.

COPYRIGHT @ 2018 by the Society of Nuclear Medicine and Molecular Imaging. DOI: 10.2967/jnumed.117.206052
}

\section{EDUCATION AND SYLLABUS}

The role of the UEMS/EBNM education and syllabus committee is to create training requirements for the specialty of nuclear medicine that comply with the standards for postgraduate medical specialist training (1). These requirements follow European Parliament and EU Council directive 2005/36/EC, which concerns the recognition of professional qualifications (4). A short version was published in the European Journal of Nuclear Medicine and Molecular Imaging (5), and the complete document was approved at a meeting of the UEMS Council in Israel on April 28, 2017, and published on the UEMS/EBNM website (www.uems.eanm.org). An important aspect of the role of the UEMS is to define the minimum training period for each specialty as $4 \mathrm{y}(6)$.

The syllabus is organized into 3 sections describing the training content and learning outcome for every field relevant to the practice of nuclear medicine. The first section includes theoretic knowledge, such as the scientific bases of nuclear medicine, and clinical knowledge, such as diagnostic imaging, therapeutic applications, practical skills, and the competencies required to practice nuclear medicine in the EU. This section also describes the organization of training in terms of schedule, curriculum, assessment, and evaluation. The second section deals with requirements for individuals who perform training, that is, the process for becoming recognized as a trainer and the management of trainer quality. The third section deals with requirements for institutions that perform training, which should fulfill both the quantitative criteria proposed in the first section and the criteria for national accreditation.

Nuclear medicine is a rapidly changing specialty. To maintain high standards in education, the education and syllabus committee is working closely with the European Association of Nuclear Medicine on a new version of the training requirements.

\section{ACCREDITATION OF NUCLEAR MEDICINE DEPARTMENTS AND TRAINING CENTERS}

To facilitate education, centers should have the capacity to perform the essential diagnostic and therapeutic procedures. The UEMS/EBNM committee for accreditation of nuclear medicine departments and training centers plays a key role in this goal by implementing an accreditation system across Europe leading to the granting of a dedicated certificate valid for 5 years. A clinical audit is required by Council Directive 97/43 EURATOM (7) and is the basis for accreditation. The audit was first created in 1997 by a 
task group, which became a permanent UEMS/EBNM committee in 2004. In 2012, accreditation of nuclear medicine departments and accreditation of nuclear medicine training centers were merged to become the responsibility of a single committee, and more than 60 nuclear medicine departments across Europe have been accredited so far. A list of the currently accredited centers is available on the UEMS/EBNM website.

The benefit of accreditation is the improvement of patient care by standardization of quality in nuclear medicine (8). Similarly, the achievement of accreditation by a training center implies that it has fulfilled the minimum criteria of the UEMS/EBNM education and syllabus committee for teachers of nuclear medicine (e.g., physicians, radiopharmacists, physicists, technologists). If a training center does not perform the full range of diagnostic and therapeutic procedures described in the UEMS/EBNM syllabus, it can be accredited only if it has a formal agreement with another accredited center that can perform the remaining procedures.

Accreditation materials were developed according to International Organization for Standardization 9001:2008 and are freely downloadable from the UEMS/EBNM website. However, alternate certification pathways exist, such as the International Atomic Energy Agency QUANUM (9) or through the national societies' clinical audits, which are less time-consuming than a full International Organization for Standardization 9001 certification. Reaccreditation is mandatory every 5 years.

\section{CME/CPD ACCREDITATION}

CME is fundamental for good medical practice and for delivering high-quality patient care. According to the UEMS charter on CME (1994, chapter 4, article 6; https://www.uems.eu/_data/assets/ pdf_file/0020/1478/174.pdf), CME represents a moral and ethical commitment for all medical specialists to ensure that the clinical care they practice is safe and based on valid scientific evidence. In 2000, the UEMS/EBNM accreditation committee was established as the scientific and technical body for the evaluation and accreditation of nuclear medicine CME/CPD activities in Europe. This committee aims to provide high-quality standards for the scientific and educational content of CME/CPD activities in nuclear medicine, ensure the transparency of $\mathrm{CME} / \mathrm{CPD}$ programs and their independence from the influence of the health-care industry, and assist national and international nuclear medicine societies in planning and implementing CME/CPD programs.

The committee follows the rules and standards of the European Accreditation Council for CME (EACCME) - the largest CME/ CPD authority in the EU, established by the UEMS in January 2000 with the goal of harmonizing accreditation in the EU and of creating the premises for mutual recognition of EACCME credits throughout European countries. There is great added value to obtaining EACCME accreditation for an educational event. EACCME credits are recognized in most EU countries and in the United States (through the American Medical Association) and Canada (through the Royal Colleges of Physicians and Surgeons of Canada). EACCME credits represent a guarantee of quality for patients, employers, and regulatory bodies. Moreover, EACCME credits represent the best measurable means for nuclear medicine specialists to demonstrate that they continue to meet the criteria for high-quality patient care, particularly in this era of cross-border health care with a pan-European right to treatment for patients, competitive health-care markets, cross- border mobility of medical specialists, and increasing need to improve skills and competencies and to gain professional qualifications recognized throughout Europe. The accreditation process is completely online at www.eaccme.uems.eu. The accreditation portfolio is complete, including all forms of modern educational activities to be accredited (congresses, conferences, courses, seminars, webinars, workshops, and e-learning materials such as modules, apps, web platforms, and web libraries) or recognized (EACCME-recognized activities such as reviewing and publishing articles or becoming an examiner in a UEMS/ EBNM examination).

\section{FELLOWSHIP EXAMINATION}

The UEMS/EBNM fellowship examination committee plays an important role in demonstrating that an individual has a sufficient level of knowledge to practice as an independent European nuclear medicine specialist. This demonstration is accomplished through a common examination, which is presently performed on an individual and voluntary basis. The UEMS/EBNM fellowship examination was introduced in 1993. According to the Glasgow declaration of the UEMS in 2007 (10), this examination is open to candidates from UEMS and non-UEMS countries. Its main objective is to achieve and maintain the highest standards in nuclear medicine. Applicants must be acknowledged specialists in their country and must provide both proof of education and proof of currently valid postgraduate CME. Furthermore, they should refer to the published European training requirements in nuclear medicine with respect to the number of procedures in all fields, including therapy and hybrid imaging. Eligibility is checked by the UEMS/EBNM fellowship examination committee. The examination takes place twice a year, once in Vienna in the spring and again at the annual congress of the European Association of Nuclear Medicine in the fall. On the first day, a session is offered to prepare the candidates for the written part of the examination. This preparation session, which familiarizes them with the examination form, the environment, and the examiners, is well attended and very much appreciated. After a short break, a 3-h examination with 140 multiple-choice questions follows. Only candidates who succeed on this written test are eligible for the oral test-a 30- to 45-min evaluation of their skills and attitude - on the next day.

Even though the UEMS/EBNM fellowship examination is not mandatory, an increasing number of candidates have applied since it was created. Approximately half are from non-UEMS countries, mostly in south Asia. In 2014, the UEMS/EBNM fellowship examination committee was invited by the Asian Nuclear Medicine Board (ANMB) for a first meeting about the ANMB's fellowship examination. The ANMB and the UEMS/EBNM share strong similarities in terms of the different levels of medical education, different curricula, and different cultures and languages among their member countries. On the basis of this first fruitful experience, a collaboration was started, and the UEMS/EBNM will soon rejoin the ANMB to again assess the fellowship examination according to the recommendation for continuous assessment of both examinations and examiners.

The UEMS/EBNM has an important role in shaping the future of nuclear medicine in Europe by setting the standards of education for young nuclear medicine specialists and by proving that the knowledge of older specialists is in accord with today's standards. We at the UEMS/EBNM offer our knowledge and 
experience to our colleagues at the Society of Nuclear Medicine and Molecular Imaging for structuring the educational requirements in the United States.

\section{DISCLOSURE}

No potential conflict of interest relevant to this article was reported.

\section{REFERENCES}

1. History of UEMS. European Union of Medical Specialists website. https://www. uems.eu/about-us/presentation/history. Accessed December 14, 2017.

2. Standards. World Federation for Medical Education website. http://wfme.org/ standards/. Accessed December 14, 2017.

3. Costa DC. UEMS/EBNM endeavour. Eur J Nucl Med Mol Imaging. 2012;39:737-738.

4. Directive 2005/36/EC of the European Parliament and of the Council of 7 September 2005 on the recognition of professional qualifications. EUR-Lex website.
http://eur-lex.europa.eu/legal-content/EN/TXT/?uri=celex\%3A32005L0036. Accessed December 14, 2017.

5. Prigent A, Hustinx R, Costa DC. Nuclear medicine training in the European Union: 2015 update. Eur J Nucl Med Mol Imaging. 2016;43:583-596.

6. Training requirements for the specialty of nuclear medicine. European Union of Medical Specialists website. https://www.uems.eu/_data/assets/pdf_file/0017/43523/UEMSEuropean-Training-Requirements-NUCMED-final.pdf. Accessed December 14, 2017.

7. Council Directive 97/43/Euratom of 30 June 1997 on health protection of individuals against the dangers of ionizing radiation in relation to medical exposure, and repealing Directive 84/466/Euratom. European Union website. https://publications. europa.eu/en/publication-detail/-/publication/aa7564fa-fd07-4872-943c-66df8f4f1099/ language-en. Accessed December 14, 2017.

8. García-Burillo A, Hilson A, Mirzaei S. Why do we need accreditation of nuclear medicine departments? Eur J Nucl Med Mol Imaging. 2012;39:1643-1645.

9. QUANUM 2.0, Excel tool and QNUMED. International Atomic Energy Agency website. https://humanhealth.iaea.org/HHW/NuclearMedicine/QUANUM_2.0_Excel_ Tool_and_QNUMED/index.html. Accessed December 14, 2017.

10. Glasgow Declaration. European Union of Medical Specialists website. https://www. uems.eu/_data/assets/pdf_file/0009/1242/Glasgow_Declaration_-_February_2007. pdf. Accessed December 14, 2017. 